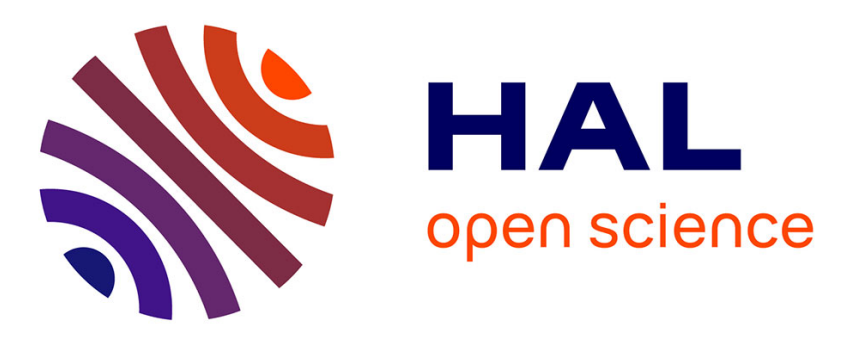

\title{
A first outlook of sputtered FeWO4 thin films for micro-supercapacitor electrodes
}

Gaëtan Buvat, Antonella Iadecola, Florent Blanchard, Thierry Brousse, Pascal Roussel, C. Lethien

\section{To cite this version:}

Gaëtan Buvat, Antonella Iadecola, Florent Blanchard, Thierry Brousse, Pascal Roussel, et al.. A first outlook of sputtered FeWO4 thin films for micro-supercapacitor electrodes. Journal of The Electrochemical Society, 2021, 168 (3), pp.030524. 10.1149/1945-7111/abec57 . hal-03194252

\section{HAL Id: hal-03194252 \\ https://hal.science/hal-03194252}

Submitted on 12 Apr 2021

HAL is a multi-disciplinary open access archive for the deposit and dissemination of scientific research documents, whether they are published or not. The documents may come from teaching and research institutions in France or abroad, or from public or private research centers.
L'archive ouverte pluridisciplinaire HAL, est destinée au dépôt et à la diffusion de documents scientifiques de niveau recherche, publiés ou non, émanant des établissements d'enseignement et de recherche français ou étrangers, des laboratoires publics ou privés. 


\section{A First Outlook of Sputtered $\mathrm{FeWO}_{4}$ thin films for Micro- Supercapacitor Electrodes}

Gaëtan Buvat ${ }^{1,2,{ }^{*}, \text { Antonella ladecola }}{ }^{2}$, Florent Blanchard ${ }^{3}$, Thierry Brousse ${ }^{2,4,{ }^{*} \text {, }}$ Pascal Roussel ${ }^{3}$, Christophe Lethien ${ }^{1,2,{ }^{*}}$

1 Université de Lille, CNRS, Centrale Lille, Université Polytechnique Hauts-deFrance, UMR 8520 - IEMN, F-59000 Lille, France

${ }^{2}$ Réseau sur le Stockage Electrochimique de l'Energie (RS2E), CNRS FR 3459, 33 rue Saint Leu, 80039 Amiens Cedex, France

${ }^{3}$ Unité de Catalyse et de Chimie du Solide (UCCS), Université de Lille, CNRS, Centrale Lille, Université d'Artois, UMR 8181 - UCCS, F-59000 Lille, France

4 Institut des Matériaux Jean Rouxel (IMN), CNRS UMR 6502 - Université de Nantes, 2 rue de la Houssinière BP32229, 44322 Nantes cedex 3, France

*Correspondence to: christophe.lethien@univ-lille.fr, gaetan.buvat@iemn.fr and Thierry.brousse@univ-nantes.fr

Keywords: $\mathrm{FeWO}_{4}$, multicationic oxides, thin films, sputtering, microsupercapacitors, pseudocapacitance 


\section{ABSTRACT}

The next generation of Internet of Things devices requires micro-supercapacitors operating at high voltage which is difficult to achieve using symmetrical design. Thus, their fabrication in an asymmetric configuration is mandatory. While $\mathrm{MnO}_{2}$ is wellestablished as positive electrode, the scarcity of existing efficient materials able to be used at the negative side drives the research towards new promising materials. Since few years, a new class of oxide materials, named multicationic oxides, were demonstrated to be attractive solutions as bulk electrodes for electrochemical capacitor. Among them, the wolframite-type $\mathrm{FeWO}_{4}$ oxide was proposed as an interesting negative electrode material for asymmetric $\mathrm{FeWO}_{4} / \mathrm{MnO}_{2}$ electrochemical capacitors. The present paper reports for the first time on the successful thin film synthesis of such iron-tungstate oxide films by reactive DC magnetron sputtering, a deposition method widely used in the semiconductor industry to manufacture micro-devices. The pseudocapacitive behaviour documented at the bulk scale is preserved at the thin film level as well, and opens-up the possibility to use $\mathrm{FeWO}_{4}$ in the next generations of micro-supercapacitors. 


\section{INTRODUCTION}

The progress of miniaturized sensors in various domains from medical to environmental sciences is at the core of upcoming innovations. It belongs to the vast technological Internet of Things (IoT) concept and it relies on the development of an eco-system of miniaturized self-connected devices [1, 2]. This ubiquitous concern goes hand in hand with the spread of the fifth generation mobile communication standard for broadband cellular networks (5G) [3]. Reliability of such sensors depends among other factors on their ability to be self-powered and maintenancefree. For this reason, they require to be integrated together with miniaturized energy autonomous system, where harvested energy coming from the environment (issued from solar, motion, thermal, or radiofrequency sources) is used to charge miniaturized electrochemical energy storage systems [4, 5]. Among them, microsupercapacitors (MSC) are a class of miniaturized electrochemical capacitor with a reduced footprint surface (typically a few several $\mathrm{mm}^{2}$ ) for high power applications. However, the low energy density of such MSC as well as the use of deposition techniques of active materials that are not compatible with microelectronic jeopardize the scaling-up of such technology for mass production [6, 7]. Increasing the energy density of such MSC is performed by maximizing either (both) the capacitance value, or (and) the cell voltage. On one hand, porous carbon based MSCs exhibit an interesting cell voltage close to $3 \mathrm{~V}$. On the other hand, the surface capacitance values of such carbon-based electrodes are unfortunately limited by the storage mechanism that mainly relies on capacitive ions adsorption/desorption process [8$10])$, and also by the low amount of active material involved in thin-film electrodes. To improve the capacitance, pseudocapacitive materials are interesting alternatives as their charge storage mechanism arises from fast redox processes occurring at the 
surface or sub-surface of active materials associated to a capacitive-like electrochemical signatures (pseudocapacitive) [9, 11, 12]. Commonly used pseudocapacitive materials are transition metals oxides like $\mathrm{RuO}_{2}$ and $\mathrm{MnO}_{2}$. Thin film electrodeposition of such oxides on 3D scaffolds were already demonstrated in the last decade as efficient electrodes to improve the capacitance values of micro devices, but the cell voltage of MSCs implementing such electrodes stays close to 1 V [13-16]. Despite these improvements, energy density of micro-supercapacitors are still limited at ca. $100 \mu$ Wh.cm ${ }^{-2}$ for the most efficient of them.

As the energy density of micro-supercapacitors depends of the square of the cell voltage, the fabrication of an asymmetric MSC with enhanced cell voltage would greatly increase the energy density $[17,18]$. This configuration requires using different active materials in the two electrodes, with complementary electrochemical potential windows. Among the existing pseudocapacitive materials, scarce are those that can be employed versus $\mathrm{MnO}_{2}$ or $\mathrm{RuO}_{2}$, namely, that have an electrochemical potential that can be used as a negative electrode. Indeed, only a few asymmetric thin-film based MSC and hybrid micro-device have been reported, such as $\mathrm{VN} / \mathrm{RuO}_{2}$ [19] and VN / NiO [20], respectively. In the field of bulk-derived supercapacitor, few examples can be found such as $\mathrm{VN} / \mathrm{MnO}_{2}$ [21], or $\mathrm{Fe}_{3} \mathrm{O}_{4} / \mathrm{MnO}_{2}[22,23]$, but with very limited cycling ability.

Apart from single transition metal oxides mentioned above, multicationic oxides have also been reported as potential pseudocapacitive electrode for supercapacitor [24]. They include several cations in their crystallographic structure which can act either as active redox centres, or as spectator cations. Wolframite-type $\mathrm{FeWO}_{4}$ oxide for example can be a good candidate as pseudocapacitive electrode material for which $\mathrm{Fe}^{3+} / \mathrm{Fe}^{2+}$ redox couple has been evidenced to be involved in the charge storage 
mechanism $[25,26]$. Although, tungsten cation is found to be electrochemically inactive, it might play a role in keeping the stability of the oxide structure upon cycling. As a matter of fact, $\mathrm{FeWO}_{4}$ was investigated as a negative electrode in bulk asymmetric supercapacitors, exhibiting over more than 40000 cycles when coupled with a $\mathrm{MnO}_{2}$ positive electrode, and over 45000 cycles with $\mathrm{Ba}_{0.5} \mathrm{Sr}_{0.5} \mathrm{Co}_{0.8} \mathrm{Fe}_{0.2} \mathrm{O}_{3}$ (another multicationic oxide), both asymmetric devices showing a cell voltage of 1.4 $\mathrm{V}[27,28]$. Subsequently, $\mathrm{FeWO}_{4}$ appears to be a promising candidate as negative electrode material for asymmetric micro-supercapacitor. However, no data are available on the deposition of thin films of this compound, with deposition techniques compatible with microelectronic facilities.

The present paper demonstrates the synthesis of $\mathrm{FeWO}_{4}$ films using $\mathrm{DC}$ magnetron sputtering in reactive atmosphere, which is a physical vapour deposition method compatible with the microelectronic facilities. It is however challenging to stabilize such compound as a pure phase when several cations are involved with different possible oxidation states $(+2$ and +6 , avoiding +3 and +5 for iron and tungsten, respectively). Iron-tungstate $\mathrm{FeWO}_{4}$ was never deposited as a thin film electrode, but clues of its possible stabilization was given by Zhou et al. who were able to isolate this phase in a combinatorial $\mathrm{Fe}-\mathrm{W}-\mathrm{Bi}$ co-sputtering deposition, but for a different application [29]. The present work shows for the first time the successful synthesis of pure $\mathrm{FeWO}_{4}$ films by $\mathrm{DC}$ magnetron reactive sputtering, as well as related electrochemical characterizations. 


\section{METHODS}

Thin films deposition methods: Mixed iron/tungsten oxide thin films were grown by reactive direct current (DC) magnetron sputtering from an equimolar $\mathrm{Fe} / \mathrm{W}$ metallic target (diameter 4 inch, 99.9\%, Neyco), and under a mixed argon/oxygen atmosphere. The depositions were performed using a CT200 Alliance Concept reactor, with a base pressure vacuum chamber below $10^{-6}$ mbar. The distance between the target and the substrate holder was kept constant at $6 \mathrm{~cm}$. Power density and temperature, during deposition, were fixed at $1.2 \mathrm{~W} . \mathrm{cm}^{-2}$ and room temperature, respectively. For the purpose of this work, pressure and oxygen content diluted in argon were varied between 0.006 and 0.03 mbar, and 2.5 and $12.5 \%$, respectively. Oxygen content was deduced from the flow rate (in sccm) ratio $\mathrm{O}_{2} /\left(\mathrm{O}_{2}\right.$ + Ar). Depositions were carried out on (100) silicon substrates preliminarily coated with an $80 \mathrm{~nm}$-thick $\mathrm{Al}_{2} \mathrm{O}_{3}$ layer and with a $50 \mathrm{~nm}$-thick platinum film. The Pt layer, evaporated using a Plassys MEB 550S apparatus, was used as a current collector; while the $\mathrm{Al}_{2} \mathrm{O}_{3}$ film was used as a diffusion barrier to prevent the Pt-Si interdiffusion responsible for the formation of a brittle (Pt, Si) alloy and was deposited by atomic layer deposition (ALD) in a Picosun R200 reactor.

Structural analyses: Crystal structure was analyzed by X-ray diffraction using a Rigaku Smartlab diffractometer equipped with a $9 \mathrm{~kW}$ rotating anode. A BraggBrentano configuration equipped with a Hypix detector, recording in 1D mode, was used with a $\mathrm{Cu} \mathrm{Ka}_{1+2}$ radiation, and an offset of $2^{\circ}$ relatives to the substrate was applied to avoid a saturation of the detector due to the high intensity of the (100) silicon reflection. Step recording was $0.01^{\circ}$.step ${ }^{-1}$ for room temperature patterns, as well as for high temperature in-situ thermodiffraction performed in an Anton-Paar 
DHS1100. Refinements of cell parameters were carried out using the program JANA $2006[30]$.

Morphological analyses: Cross section morphology and thickness of the films were observed with a Zeiss Ultra 55 scanning electron microscope (SEM). To calculate the relative density of the films, mass samples were quantified with an electronic microbalance apparatus from Mettler Toledo (100 ng accuracy), and the surface areas were measured with the program ImageJ [31].

X-ray Absorption Spectroscopy analyses: The XAS experiment was performed at the ROCK beamline of synchrotron SOLEIL (France) [32]. The photons emitted from the bending magnet were selected using a Si(111) quick-XAS channel-cut monochromator for acquisitions at Fe K-edge (7112 eV) and W $L_{3}$-edge (10 $\left.200 \mathrm{eV}\right)$. First, Fe foil and $\mathrm{WO}_{2}$ pellet were measured in transmission mode to calibrated the incident energy, and in particular respect to the glitches of the Si(111) crystal. Then, the XAS spectra were acquired in fluorescence mode using a PIPS detector first at Fe and then at $W L_{3}$-edge, with an oscillation frequency of $2 \mathrm{~Hz}$ of the quick-XAS monochromator, and an acquisition averaged over 5 minutes. The $\mathrm{FeWO}_{4}$ sample was placed at $50^{\circ}$ in respect to the incident beam, while the detector was in backscattering configuration to avoid the intense Bragg peaks from the substrate. The energy calibration and normalization were done using the Demeter package [33].

Electrochemical analyses: A one-compartment biologic flat cell was used to perform electrochemical measurements on $\mathrm{FeWO}_{4}$ thin films using a conventional three-electrode setup. The reference electrode was a silver-silver chloride electrode $(\mathrm{Ag} / \mathrm{AgCl})$ soaked in $3 \mathrm{M} \mathrm{NaCl}$ solution, and a platinum wire was employed as counter electrode. A neutral aqueous electrolyte, $\mathrm{LiNO}_{3} 5 \mathrm{M}$, was used as electrolyte. Cyclic 
voltammetry and electrochemical impedance spectroscopy (EIS) were performed using a VMP3 potentiostat/galvanostat (Biologic). EIS spectra were measured by applying signal amplitude of $10 \mathrm{mV}$ from $200 \mathrm{kHz}$ to $10 \mathrm{mHz}$ at the open-circuit voltage and at different potentials (a polarization time of 5 minutes was applied to reach a steady-state). Electrochemical impedance spectra were fitted to equivalent circuit models using the complex nonlinear least-squares fitting program ZView [34]. 


\section{RESULTS AND DISCUSSION}

The present study aims at developing $\mathrm{FeWO}_{4}$ thin films by DC magnetron sputtering technique from metallic iron / tungsten target under $\mathrm{Ar} / \mathrm{O}_{2}$ atmosphere. To reach this goal, a two-step process is used. First, amorphous Fe-W mixed oxide thin film is deposited on $\mathrm{Si} / \mathrm{Al}_{2} \mathrm{O}_{3} / \mathrm{Pt}$ current collector. Then, the film is annealed ex situ to crystallize the expected phase (fig. 1a). Iron tungstate oxide, $\mathrm{FeWO}_{4}$, crystallizes in a wolframite-type structure composed of alternated layers of distorted $\left[\mathrm{FeO}_{6}\right]$ and $\left[\mathrm{WO}_{6}\right]$ octahedrons, where the oxidation state of iron and tungsten are +2 and +6 , respectively (fig. 1b) [35]. From an equimolar iron - tungsten metal target, $\mathrm{FeWO}_{4}$ films were then deposited by reactive sputtering under $\mathrm{Ar} / \mathrm{O}_{2}$ mixed atmosphere. As the oxygen partial pressure is a key issue in order to get the formal cations oxidation state, the relationship between pressure and oxygen content were first explored. For that purpose, power density, temperature and deposition duration were fixed at 1.2 W. $\mathrm{cm}^{-2}, 293 \mathrm{~K}$ and 15 minutes, respectively. Oxygen content in the plasma, diluted in an argon atmosphere, was then varied for different deposition pressures from 0.006 to 0.03 mbar. It can be noted that the $\mathrm{Al}_{2} \mathrm{O}_{3}$ layer was deposited to prevent chemical reaction between the Pt current collector and the silicon wafer due to the high temperature annealing process used to crystallize the $\mathrm{FeWO}_{4}$ wolframite phase [36]. As the deposited films have an amorphous structure, their corresponding crystallized phases were obtained by a heat treatment at $600^{\circ} \mathrm{C}$ during $2 \mathrm{~h}$ under vacuum. These annealing conditions were chosen according to the results presented and discussed in the subsequent paragraph. Fig. 1c depicts the phase diagram of the obtained structure, characterized by XRD, depending of the oxygen content and total pressure. From this map, four different regimes can be clearly distinguished as delimited by the

dash lines. At high oxygen content (fig. 1c, Zone I), the mixed Fe/W oxide films 
crystallize mainly in the $\mathrm{Fe}_{2} \mathrm{~W}_{3} \mathrm{O}_{12}$ form, where iron has a cation oxidation degree of +3 and tungsten +6 , consistent with an oxidizing atmosphere. On the other hand, when the oxygen content is too low (fig. 1c, Zone II), iron reacts with platinum, giving rise to an intermetallic $(\mathrm{Fe}, \mathrm{Pt})$ phase, together with a $\mathrm{WO}_{\mathrm{x}}$ tungsten oxide ( $\mathrm{x}$ varying between 3 and 2 as the oxygen partial pressure decrease), and most of the films were partially delaminated. Between these two regimes, $\mathrm{FeWO}_{4}$ is obtained as also illustrated by the XRD patterns of figure 1d. However, depending on the deposition pressure, tungsten trioxide is detected, mainly at $0.03 \mathrm{mbar}$, and in to a lower extent at 0.01 mbar (fig. 1c, Zone III). Finally, impurity-free $\mathrm{FeWO}_{4}$ is successfully obtained at 0.006 mbar and with 10 percent of oxygen (fig. 1c, Zone IV).

Thereby, $\mathrm{FeWO}_{4}$ films were herein synthesized with a total pressure of $0.006 \mathrm{mbar}$, and with a $4 \mathrm{sccm}$ oxygen flow diluted into $36 \mathrm{sccm}$ of argon (corresponding then to an oxygen content of $10 \%)$. The same conditions of power density, temperature and time deposition than before were used (i.e. $1.2 \mathrm{~W} . \mathrm{cm}^{-2}$, room temperature and 15 minutes, respectively). Phase evolution of the as-deposited sputtered film was monitored by in situ thermodiffraction under vacuum; scan and heating rate were 10 degree. $\min ^{-1}$ (between $2 \theta=13^{\circ}$ and $43^{\circ}$ ), and $3{ }^{\circ} \mathrm{C} \cdot \mathrm{min}^{-1}$, respectively. As can be seen in fig. $2 \mathrm{a}$, between room temperature and $400^{\circ} \mathrm{C}$, the film is amorphous, and the only observed reflection at ca. $2 \theta=40^{\circ}$ is the platinum (111) one. At $400{ }^{\circ} \mathrm{C}$, beside a shift of this latter peak demonstrating the chemical reactivity of the current collector with iron, as previously mentioned when low oxygen content is used, a sudden phase crystallization occurs. Several attempts to identify this phase(s) using the 2021 version of ICDD PDF4+ database were unsuccessful. Though, it is out of the scope of the present study to solve the structure of this intermediate product, this unknown phase could be indexed with an orthorhombic space group Pcma (see fig. 
S1) using the DICVOL2006 program [37]. At $687^{\circ} \mathrm{C}$, the expected $\mathrm{FeWO}_{4}$ phase crystallizes and its structure can be indexed with the JCPDS card $n^{\circ} 01-074-1130$. A remaining impurity from the intermediate reaction phase is also detected. Beyond that temperature and after cooling back down to room temperature, $\mathrm{FeWO}_{4}$ structure is stable. In the next step, post-deposition annealing under vacuum was reproduced into a tubular furnace. An offset of $90^{\circ} \mathrm{C}$ was observed between the two heating systems, where the crystallisation occurred at $600{ }^{\circ} \mathrm{C}$ after 2 hours and with a heating rate of $5^{\circ} \mathrm{C} \cdot \mathrm{min}^{-1}$. XRD pattern of the thin film (fig. 2b) shows a pure phase, with lattice parameters close to those previously reported [25, 35, 38]. It can be noted that no tungsten/iron metals or binaries oxides reflections can be observed, in the limit of detection of the $\mathrm{XRD}$, revealing a good reactivity with the oxygen atmosphere during the magnetron sputtering deposition process. The oxidation states of $\mathrm{Fe}$ and $\mathrm{W}$ in the sputtered $\mathrm{FeWO}_{4}$ films were probed by X-ray Absorption Near-Edge Structure (XANES). Fig. 2c shows the Fe K-edge XANES of $\mathrm{FeWO}_{4}$ together with references materials $\mathrm{Fe}_{2} \mathrm{O}_{3}\left(\mathrm{Fe}^{3+}\right), \mathrm{Fe}_{3} \mathrm{O}_{4}\left(\mathrm{Fe}^{2.67+}\right)$, and Mohr's salt $\left(\mathrm{NH}_{4}\right)_{2} \mathrm{Fe}\left(\mathrm{SO}_{4}\right)_{2}$ $\left(\mathrm{Fe}^{2+}\right)$. The energy position at 0.7 of the normalized absorption was plotted versus the formal valence (fig. $\mathbf{2 c}$ - inset) to retrieve information on the Fe oxidation state. Using this method, Fe mean oxidation state in $\mathrm{FeWO}_{4}$ film is found to be +2.3 . In fig. 2d, the $\mathrm{W} \mathrm{L}_{3}$-edge XANES spectra of $\mathrm{FeWO}_{4}$ is reported, along with references $\mathrm{WO}_{2}$ and $\mathrm{WO}_{3}$. The $\mathrm{W} \mathrm{L}_{3}$-edge white line $(\mathrm{WL})$ is representative of the electronics transition from the $2 p_{3 / 2}$ core level to the empty $5 d$ state [39], and its broadening is mainly due to the splitting of $5 d$ levels into the $t_{2 g}$ and $e_{g}$ orbitals for the effect of the crystal field [39]. It can be seen from the inset that the maximum of the first derivative of the $\mathrm{FeWO}_{4}$ overlaps with the $\mathrm{WO}_{3}$ reference sample. Moreover, the second derivative curves (figure S2) of $\mathrm{FeWO}_{4}$ and $\mathrm{WO}_{3}$ are similar. These findings 
demonstrate that the tungsten in $\mathrm{FeWO}_{4}$ adopts a similar configuration than in $\mathrm{WO}_{3}$, made of slightly distorted $\left[\mathrm{WO}_{6}\right]$ octahedron with tungsten oxidation state close to +6 . The obtained oxidation state of iron and tungsten are in agreement to those expected for the bulk material, used as an efficient electrode for electrochemical capacitors [26]. These results are also fully consistent with a thorough study recently reported on the electronic structure of $\mathrm{FeWO}_{4}$ in which the pseudocapacitive behavior of $\mathrm{FeWO}_{4}$ was predicted to be linked to the formation of hole polarons at the Fe-sites together with dominant native point defects on the iron sites [40]. According to XAS findings, the iron tungstate can be written as non-stoichiometric $\mathrm{Fe}_{0.87} \mathrm{WO}_{4}$.

The microstructure of the film was characterized by cross section SEM analyses. Fig. $2 \mathrm{e}$ illustrates the morphology of the $\mathrm{FeWO}_{4}$ film (deposition time $=15$ minutes), before and after post-deposition annealing at $600{ }^{\circ} \mathrm{C}$ during $2 \mathrm{~h}$ under vacuum. Prior to the annealing step, the film presents a dense microstructure, which is classically observed for such sputtered condition at this pressure level and power density [41]. The annealed $\mathrm{FeWO}_{4}$ film is still exhibiting a compact morphology, in addition to a homogeneous dispersion of closed porosities, and the thickness is around $900 \mathrm{~nm}$. The relative calculated density, as described in the experimental section, is ca. $90 \%$. Also, as mentioned previously, it can be observed that the platinum layer has reacted with the iron issued from the $\mathrm{FeWO}_{4}$ film owing to the annealing process.

The electrochemical behavior of $\mathrm{FeWO}_{4}$ film was investigated by cyclic voltammetry $(\mathrm{CV})$ in neutral aqueous electrolyte $\left(5 \mathrm{M} \mathrm{LiNO}_{3}\right)$ at different sweep rates (fig. $\left.3 \mathbf{a}\right)$. The electrochemical window of $\mathrm{FeWO}_{4}$ film was restricted between -0.6 to $0 \mathrm{~V}$ (vs. $\mathrm{Ag} / \mathrm{AgCl})$. This potential range is actually in good agreement with the one reported for the $\mathrm{FeWO}_{4}$ bulk counterpart [25], as validated in fig. S3a which presents its full stability range. The potential below $-0.6 \mathrm{~V}$ is limited by the concomitant hydrogen 
evolution reaction (HER) and the irreversible reduction of $\mathrm{Fe}^{2+}$ into metallic iron [42]. Above $0 \mathrm{~V}$, the electrochemical activity is poor in contrast to the -0.6 and $0 \mathrm{~V}$ potential window. The corresponding areal and volumetric capacitance values dependence with the sweep rates are shown in fig. $\mathbf{3 b}$. The quasi-rectangular shape voltammograms correspond to what is typically obtained for a capacitive material whatever the sweep rates. More specifically, the CV curves are comparable to those reported earlier for nanocrystalline $\mathrm{FeWO}_{4}$ material [25]. The areal and volumetric capacitance values are $3.49 \mathrm{mF} . \mathrm{cm}^{-2}$ and $36.7 \mathrm{~F}_{\mathrm{cm}} \mathrm{cm}^{-3}$ at $10 \mathrm{mV} . \mathrm{s}^{-1}$, respectively. The double-layer capacitances calculated on high-surface area carbon powders reach values of ca. $20 \mu \mathrm{F} . \mathrm{cm}^{-2}$ [43]. Thus, double layer capacitance cannot explain the charge storage mechanism of $\mathrm{FeWO}_{4}$ electrode. That is to say, the areal capacitance measured on sputtered $\mathrm{FeWO}_{4}$ films is related to pseudocapacitive charge storage processes occurring within the highly dense microstructure of the films. Comparatively, the bulk nanosized $\mathrm{FeWO}_{4}$ material synthesized by the polyol process reached a volumetric capacitance close to ca. $260 \mathrm{~F} . \mathrm{cm}^{-3}$ at $10 \mathrm{mV} \cdot \mathrm{s}^{-1}$ [25]. The dense microstructure of the sputtered $\mathrm{FeWO}_{4}$ film (density ca. $90 \%$ ) leads to a poor specific surface area while the nanosized $\mathrm{FeWO}_{4}$ material shows a high surface area $\left(85 \mathrm{~m}^{2} \cdot \mathrm{g}^{-1}\right.$ with particle size of $\left.15 \mathrm{~nm}\right)$. The kinetics of the electrolyte ions within the sputtered $\mathrm{FeWO}_{4}$ film was then studied to check if the electrochemical process is not limited by solid-state diffusion. Indeed, assuming that the current obeys the wellknown power law relationship with the sweep rate $\left(l_{\text {peak }}=a \cdot v^{b}\right.$ where $v$ is the potential sweep rate $\left(m V . s^{-1}\right)$, I the current $(A)$, and a, b parameters related to the electrode), the b-coefficient was extracted at the potential of $-0.4 \mathrm{~V} v$ s. $\mathrm{Ag} / \mathrm{AgCl}$ (fig. S3b) [44]. The b-value stays close to ca. $0.90-0.95$ for the cathodic and anodic current, 
respectively, as expected for an electrochemical capacitor electrode and corresponding to a fast charge storage process not limited by the diffusion.

Evolution of the capacity retention and coulombic efficiency over 10000 cycles can be seen in fig. $3 c$. The CV curves at $20 \mathrm{mV} . \mathrm{s}^{-1}$ for the $10^{\text {th }}$ and $10000^{\text {th }}$ cycles are reported in the inset of fig. 3c. Long term cycling shows stable capacity retention, as well as a coulombic efficiency close to $90 \%$. As a matter of fact, due to its rectangular shape, the voltammogram of the $10000^{\text {th }}$ cycle is still characteristic of a capacitivelike behavior. However, during the first cycles, an additional cathodic charge is observed on the $\mathrm{CV}$, which is also responsible of a coulombic efficiency in the range of $40-80 \%$. Such activity could be attributed to some $\mathrm{Li}^{+}$or $\mathrm{H}^{+}$trapped in the material, as reported by Goubard-Bretesché et al. [26], but it could also be related to the onset reaction of the hydrogen evolution reaction.

The pseudocapacitive charge storage mechanism of sputtered $\mathrm{FeWO}_{4}$ film was further investigated by electrochemical impedance spectroscopy (EIS). The EIS study was performed at the open circuit voltage and at different potential, as represented by the Nyquist Plots in fig. 3d. From these spectra, two main contributions can be distinguished, one at low frequency related to the capacitive behaviour of the $\mathrm{FeWO}_{4}$ material, and a second one at high frequency (inset) identified by a semicircle. This latter is often associated, depending of the nature of the material, to the charge transfer and/or to an interfacial resistance [45]. In the case of capacitive materials displaying charge storage process only based on ion adsorption / desorption in porous electrodes, charge transfer can be ruled out and no semicircle in the highfrequencies region should be found. If the Nyquist plot exhibits such contribution, it could be then related either to a charge transfer mechanism of a pseudocapacitive material, or to an interfacial resistance. Interfacial impedance values do not change 
as a function of the applied potentials. Though, it will not be the case for the charge transfer resistance $\left(R_{C T}\right)$, which should display dependence toward the applied potential. For that purpose, impedance spectra were fitted according to the model described in the supporting information (fig. S4), where the resistance related to the semicircle was extracted and was plotted versus the applied potential in fig. $\mathbf{3 d}$. Unsurprisingly, the semicircle observed seems indeed related to a charge transfer, as the $R_{C T}$ value has a monotonic decrease when the potential goes down to more reductive values, in agreement with the larger amount of $\mathrm{Fe}^{2+}$ as the potential decreases.

The performance of micro-devices (either planar or 3D) are intrinsically limited by the low footprint area (typically less than $1 \mathrm{~cm}^{2}$ ) [6, 7], and as expected, the capacitance values of micro-supercapacitors strongly depend on the amount of active material deposited. For planar micro-supercapacitor, increasing the thickness of sputtered films is one possible way to reach this goal; but this comes along with some kinetic limitation for thicker film and delamination issues. Albeit, the films developed herein have a low porosity, an overview of the electrochemical properties toward $\mathrm{FeWO}_{4}$ thickness is then pursed in this following section. The cross section SEM images of various $\mathrm{FeWO}_{4}$ films with different thicknesses are depicted in fig. S5. The thickness of the electrodes ranges from ca. 800 to $3000 \mathrm{~nm}$ for a time deposition going from 13 to 50 minutes giving rise to a linear growth rate of around $1 \mathrm{~nm} . \mathrm{s}^{-1}$. All the sputtered films exhibit the same dense morphology, and a delamination was observed for films thicker than $3 \mu \mathrm{m}$ after the annealing process. Fig. 4a shows the voltammograms at $20 \mathrm{mV} \cdot \mathrm{s}^{-1}$, and the quasi-rectangular shape observed from the CVs is preserved for all the films. The areal capacitance was extracted from the CV plots and was reported in fig. 4b. Whatever the sweep rates used, its values increases 
concomitantly with the thickness. Hence, the capacitance enhancement is thus related to an increase of the amount of active material. However, at high sweep rate, thicker films reach a plateau for a combined effect of the kinetic limitation due to the dense microstructure and the films thickness. This constraint can be appreciated with the b-coefficient calculated from the power law and depicted in fig. 4c. Subsequently, it seems that ions-diffusion within the dense sputtered $\mathrm{FeWO}_{4}$ films is limited as the b-coefficient decreases with the thickness. The b-value drops close to ca. $0.7-0.8$ for thicker films and could be related to an ohmic contribution at high sweep rate, as $\mathrm{FeWO}_{4}$ is a p-type semi-conductor [40].

Indeed, the performance reported in the present study are related to dense sputtered $\mathrm{FeWO}_{4}$ thin films. Enhancing the surface area of such films should be the mandatory next step to attain high capacitance values, as well as fast charge transfer process. It is well known from the Thornton diagram [41] that the pertinent choice of sputtering parameters (such as power, pressure, temperature etc.) is an attractive solution, although challenging when multi-cations are involved, to finely tuned the growth of sputtered porous film with feathers or columns morphologies for instance [46-48]. Suitable microstructure would enable to reach the expected performance needed for the next generation of asymmetric micro-supercapacitors.

\section{CONCLUSION}

Iron-tungsate oxide thin film, $\mathrm{FeWO}_{4}$, has been herein successfully synthesized by a two-step approach, where amorphous Fe-W mixed oxide was first deposited by DC magnetron sputtering, followed by an ex situ high temperature annealing. X-ray diffraction technique and X-ray absorption near edge spectroscopy have confirmed 
that the deposited-film adopts the wolframite-type structure, with the expected Fe and W oxidation state. The electrochemical behavior tested in neutral aqueous media shows a capacitive-like behavior of the CV related to a charge-transfer, as measured by electrochemical impedance spectroscopy. The areal capacitance reached for a $900 \mathrm{~nm}$-thick film $\left(3.5 \mathrm{mF} . \mathrm{cm}^{-2}\right.$ at $\left.10 \mathrm{mV} . \mathrm{s}^{-1}\right)$ is promising regarding the highly dense microstructure of the film, as well as a cycling ability measured over 10000 cycles. Further improvements could be expected by tuning the microstructure of the films. However, this will require to find a tradeoff between the purity of deposited phase and the increase in porosity. This work proves that multicationic compounds for microsupercapacitor application can be obtained using deposition methods compatible with microelectronic facilities, paving the way to explore new other electrode materials in the near future. 


\section{ACKNOWLEDGMENTS}

This research is financially supported by the FAMICA project from Région Haut de France. The authors also want to thank the ANR STORE-EX and the French network on electrochemical energy storage (RS2E) for the financial support. The French RENATECH network is greatly acknowledged for the use of microfabrication facilities. Chevreul Institute (FR 2638) is also acknowledged for the access to advanced characterization facilities. The XAS experiment was performed at ROCK beamline (financed by the French National Research Agency (ANR) as a part of the "Investissements d'Avenir" program, reference: ANR-10-EQPX-45) at SOLEIL Synchrotron (proposal 20191534).

\section{DATA AVALAIBILITY}

The raw/processed data required to reproduce these findings cannot be shared at this time as the data also forms part of an ongoing study.

\section{COMPETING INTERESTS}

The authors declare no competing interests.

\section{MATERIALS \& CORRESPONDENCE}

Correspondence to Christophe Lethien, Gaëtan Buvat and Thierry Brousse. 


\section{REFERENCES}

1. Atzori, L.; A. lera; G. Morabito, The Internet of Things: A survey, Computer Networks, 2010, 54(15), 2787-2805

2. Gubbi, J.; R. Buyya; S. Marusic; M. Palaniswami, Internet of Things (IoT): A vision, architectural elements, and future directions, Future Generation Computer Systems, 2013, 29(7), 1645-1660

3. Li, S.; L.D. Xu; S. Zhao, 5 G Internet of Things: A survey, Journal of Industrial Information Integration, 2018, 10, 1-9

4. Raj, A.; D. Steingart, Review-Power Sources for the Internet of Things, J. Electrochem. Soc., 2018, 165(8), B3130-B3136

5. Ryu, H.; H.-J. Yoon; S.-W. Kim, Hybrid Energy Harvesters: Toward Sustainable Energy Harvesting, Adv. Mater., 2019, 31(34), 1802898

6. Kyeremateng, N.A.; T. Brousse; D. Pech, Microsupercapacitors as miniaturized energy-storage components for on-chip electronics, Nature Nanotechnology, 2017, 12(1), 7-15

7. Lethien, C.; J. Le Bideau; T. Brousse, Challenges and prospects of 3D microsupercapacitors for powering the internet of things, Ener. Env. Sci., 2019, 12(1), 96-115

8. Simon, P.; A. Burke, Nanostructured Carbons: Double-Layer Capacitance and More, The Electrochemical Society Interface, 2008, 17(1), 38-43

9. Simon, P.; Y. Gogotsi, Perspectives for electrochemical capacitors and related devices, Nature Materials, 2020, 19(11), 1151-1163

10. Simon, P.; Y. Gogotsi, Capacitive Energy Storage in Nanostructured CarbonElectrolyte Systems, Acc. Chem. Res., 2013, 46(5), 1094-1103

11. Brousse, T.; D. Bélanger; J.W. Long, To Be or Not To Be Pseudocapacitive?, J. Electrochem. Soc., 2015, 162(5), A5185-A5189

12. Augustyn, V.; P. Simon; B. Dunn, Pseudocapacitive oxide materials for highrate electrochemical energy storage, Ener. Env. Sci., 2014, 7(5), 1597-1614

13. Ferris, A.; D. Bourrier; S. Garbarino; D. Guay; D. Pech, 3D Interdigitated Microsupercapacitors with Record Areal Cell Capacitance, Small, 2019, 15(27), 1901224

14. Patnaik, S.G.; J. Shamsudeen Seenath; D. Bourrier; S. Prabhudev; D. Guay; D. Pech, Porous RuOxNySz Electrodes for Microsupercapacitors and Microbatteries with Enhanced Areal Performance, ACS Energy Lett., 2021, 6(1), 131-139

15. Eustache, E.; C. Douard; A. Demortière; V. De Andrade; M. Brachet; J. Le Bideau; T. Brousse; C. Lethien, High Areal Energy 3D-Interdigitated MicroSupercapacitors in Aqueous and Ionic Liquid Electrolytes, Advanced Materials Technologies, 2017, 2(10), 1700126

16. El-Kady, M.F.; M. Ihns; M. Li; J.Y. Hwang; M.F. Mousavi; L. Chaney; A.T. Lech; R.B. Kaner, Engineering three-dimensional hybrid supercapacitors and microsupercapacitors for high-performance integrated energy storage, Proceedings of the National Academy of Sciences, 2015, 112(14), 4233 
17. Shao, Y.; M.F. El-Kady; J. Sun; Y. Li; Q. Zhang; M. Zhu; H. Wang; B. Dunn; R.B. Kaner, Design and Mechanisms of Asymmetric Supercapacitors, Chem. Rev., 2018, 118(18), 9233-9280

18. Long, J.W.; D. Bélanger; T. Brousse; W. Sugimoto; M.B. Sassin; O. Crosnier, Asymmetric electrochemical capacitors-Stretching the limits of aqueous electrolytes, MRS Bull., 2011, 36(7), 513-522

19. Asbani, B.; K. Robert; P. Roussel; T. Brousse; C. Lethien, Asymmetric microsupercapacitors based on electrodeposited RuO2 and sputtered VN films, Energy Storage Materials, 2021,

20. Eustache, E.; R. Frappier; R.L. Porto; S. Bouhtiyya; J.-F. Pierson; T. Brousse, Asymmetric electrochemical capacitor microdevice designed with vanadium nitride and nickel oxide thin film electrodes, Electrochem. Commun., 2013, 28, 104-106

21. Su, Y.; I. Zhitomirsky, Hybrid MnO2/carbon nanotube-VN/carbon nanotube supercapacitors, J. Power Sources, 2014, 267, 235-242

22. Cottineau, T.; M. Toupin; T. Delahaye; T. Brousse; D. Bélanger, Nanostructured transition metal oxides for aqueous hybrid electrochemical supercapacitors, Appl. Phys. A, 2006, 82(4), 599-606

23. Brousse, T.; D. Bélanger, A Hybrid Fe[sub 3]O[sub 4]-MnO[sub 2] Capacitor in Mild Aqueous Electrolyte, Electrochem. Solid-State Lett., 2003, 6(11), A244

24. Crosnier, O.; N. Goubard-Bretesché; G. Buvat; L. Athouël; C. Douard; P. Lannelongue; F. Favier; T. Brousse, Polycationic oxides as potential electrode materials for aqueous-based electrochemical capacitors, Current Opinion in Electrochemistry, 2018, 9, 87-94

25. Goubard-Bretesché, N.; O. Crosnier; C. Payen; F. Favier; T. Brousse, Nanocrystalline FeWO4 as a pseudocapacitive electrode material for high volumetric energy density supercapacitors operated in an aqueous electrolyte, Electrochem. Commun., 2015, 57, 61-64

26. Goubard-Bretesché, N.; O. Crosnier; C. Douard; A. ladecola; R. Retoux; C. Payen; M.-L. Doublet; K. Kisu; E. Iwama; K. Naoi; F. Favier; T. Brousse, Unveiling Pseudocapacitive Charge Storage Behavior in FeWO4 Electrode Material by Operando X-Ray Absorption Spectroscopy, Small, 2020, 16(33), 2002855

27. Goubard-Bretesché, N.; O. Crosnier; G. Buvat; F. Favier; T. Brousse, Electrochemical study of aqueous asymmetric FeWO4/MnO2 supercapacitor, J. Power Sources, 2016, 326, 695-701

28. Lannelongue, P.; S. Le Vot; O. Fontaine; T. Brousse; F. Favier, Electrochemical study of asymmetric aqueous supercapacitors based on high density oxides: C/Ba0.5Sr0.5Co0.8Fe0.2O3- $\delta$ and FeWO4/Ba0.5Sr0.5Co0.8Fe0.2O3-ס, Electrochim. Acta, 2019, 326, 134886

29. Zhou, L.; A. Shinde; S.K. Suram; H.S. Stein; S.R. Bauers; A. Zakutayev; J.S. DuChene; G. Liu; E.A. Peterson; J.B. Neaton; J.M. Gregoire, Bi-Containing nFeWO4 Thin Films Provide the Largest Photovoltage and Highest Stability for 
a Sub-2 eV Band Gap Photoanode, ACS Energy Lett., 2018, 3(11), 27692774

30. Petříček, V.; M. Dušek; L. Palatinus, Crystallographic Computing System JANA2006: General features, Zeitschrift für Kristallographie - Crystalline Materials, 2014, 229(5), 345-352

31. Schneider, C.A.; W.S. Rasband; K.W. Eliceiri, NIH Image to ImageJ: 25 years of image analysis, Nature Methods, 2012, 9(7), 671-675

32. Briois, V.; C. La Fontaine; S. Belin; L. Barthe; T. Moreno; V. Pinty; A. Carcy; R. Girardot; E. Fonda, ROCK: the new Quick-EXAFS beamline at SOLEIL, Journal of Physics: Conference Series, 2016, 712, 012149

33. Ravel, B.; M. Newville, ATHENA, ARTEMIS, HEPHAESTUS: data analysis for $X$-ray absorption spectroscopy using IFEFFIT, Journal of Synchrotron Radiation, 2005, 12(4), 537-541

34. Johnson, D., ZView: a software program for IES analysis, Version, 2002, 2, 200

35. Cid-Dresdner, H.; C. Escobar, The crystal structure of ferberite, FeWO4, Zeitschrift für Kristallographie - Crystalline Materials, 1968, 127(1-4), 61-72

36. Létiche, M.; M. Hallot; M. Huvé; T. Brousse; P. Roussel; C. Lethien, Tuning the Cation Ordering with the Deposition Pressure in Sputtered LiMn1.5Ni0.5O4 Thin Film Deposited on Functional Current Collectors for LiIon Microbattery Applications, Chemistry of Materials, 2017, 29(14), 60446057

37. Boultif, A.; D. Louer, Indexing of powder diffraction patterns for low-symmetry lattices by the successive dichotomy method, J. Appl. Crystallogr., 1991, 24(6), 987-993

38. Almeida, M.A.P.; L.S. Cavalcante; C. Morilla-Santos; C.J. Dalmaschio; S. Rajagopal; M.S. Li; E. Longo, Effect of partial preferential orientation and distortions in octahedral clusters on the photoluminescence properties of FeWO4 nanocrystals, CrystEngComm, 2012, 14(21), 7127-7132

39. Yamazoe, S.; Y. Hitomi; T. Shishido; T. Tanaka, XAFS Study of Tungsten L1and L3-Edges: Structural Analysis of WO3 Species Loaded on TiO2 as a Catalyst for Photo-oxidation of NH3, J. Phys. Chem. C, 2008, 112(17), 68696879

40. Hoang, K., Polaron formation, native defects, and electronic conduction in metal tungstates, Physical Review Materials, 2017, 1(2), 024603

41. Thornton, J.A., The microstructure of sputter- deposited coatings, Journal of Vacuum Science \& Technology A, 1986, 4(6), 3059-3065

42. Barnum, D.W., Potential-pH diagrams, J. Chem. Educ., 1982, 59(10), 809

43. Pandolfo, A.G.; A.F. Hollenkamp, Carbon properties and their role in supercapacitors, J. Power Sources, 2006, 157(1), 11-27

44. Lindström, H.; S. Södergren; A. Solbrand; H. Rensmo; J. Hjelm; A. Hagfeldt; S.-E. Lindquist, Li+ Ion Insertion in $\mathrm{TiO}^{2}$ (Anatase). 2. Voltammetry on Nanoporous Films, J. Phys. Chem. B, 1997, 101(39), 7717-7722 
45. Mathis, T.S.; N. Kurra; X. Wang; D. Pinto; P. Simon; Y. Gogotsi, Energy Storage Data Reporting in Perspective-Guidelines for Interpreting the Performance of Electrochemical Energy Storage Systems, Adv. Eng. Mater., 2019, 9(39), 1902007

46. Robert, K.; C. Douard; A. Demortière; F. Blanchard; P. Roussel; T. Brousse; C. Lethien, On Chip Interdigitated Micro-Supercapacitors Based on Sputtered Bifunctional Vanadium Nitride Thin Films with Finely Tuned Inter- and Intracolumnar Porosities, Advanced Materials Technologies, 2018, 3(7), 1800036

47. Robert, K.; D. Stiévenard; D. Deresmes; C. Douard; A. ladecola; D. Troadec; P. Simon; N. Nuns; M. Marinova; M. Huvé; P. Roussel; T. Brousse; C. Lethien, Novel insights into the charge storage mechanism in pseudocapacitive vanadium nitride thick films for high-performance on-chip microsupercapacitors, Ener. Env. Sci., 2020, 13(3), 949-957

48. Létiche, M.; K. Brousse; A. Demortière; P. Huang; B. Daffos; S. Pinaud; M. Respaud; B. Chaudret; P. Roussel; L. Buchaillot; P.L. Taberna; P. Simon; C. Lethien, Sputtered Titanium Carbide Thick Film for High Areal Energy on Chip Carbon-Based Micro-Supercapacitors, Adv. Funct. Mater., 2017, 27(20), 1606813 


\section{LIST OF CAPTIONS AND FIGURE CAPTIONS}

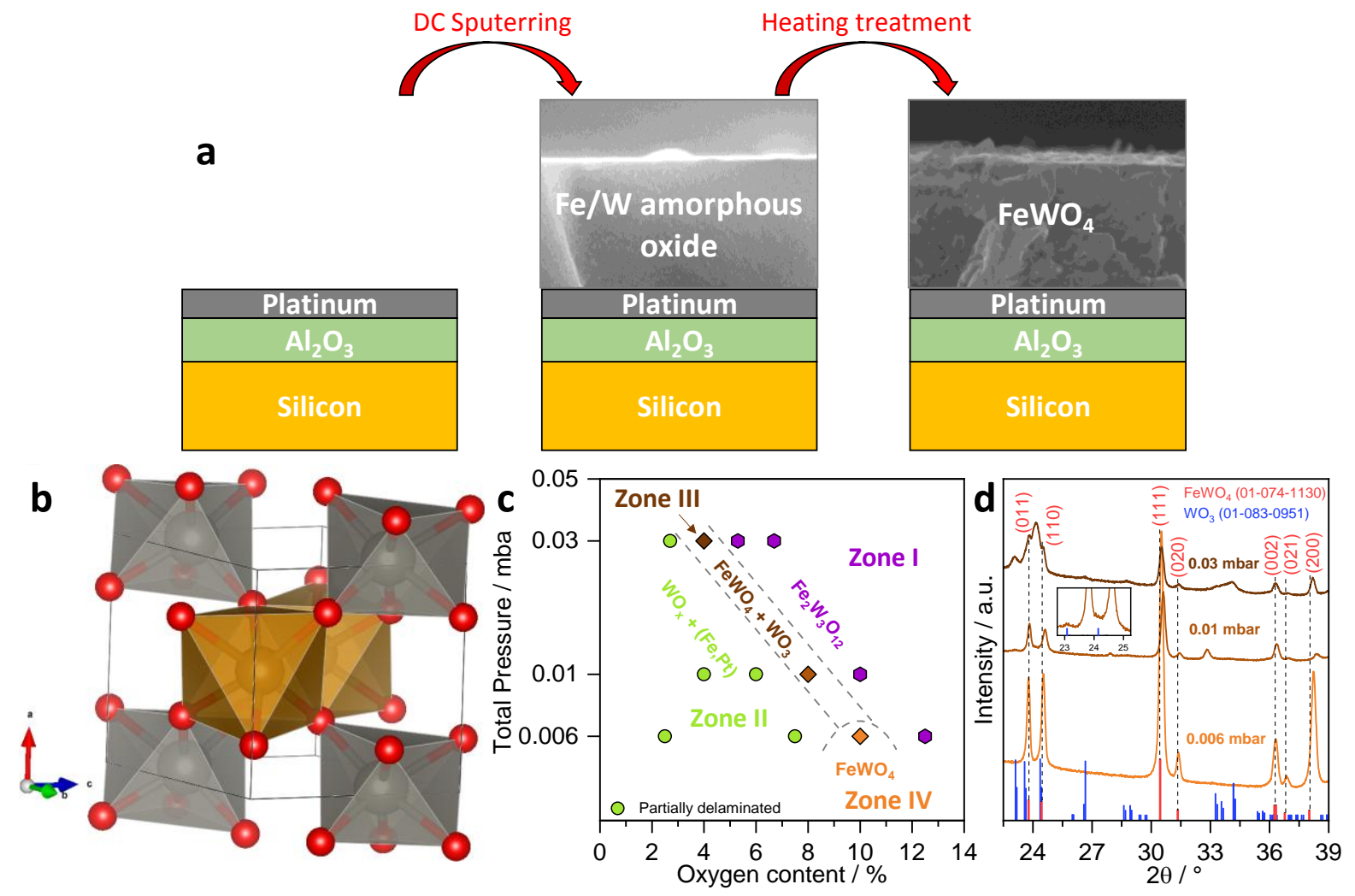

Fig. 1| Structural analyses of sputtered Fe/W mixed oxides films. a. Synthesis procedure of $\mathrm{FeWO}_{4}$ thin films based on a two-step process. b. Crystal structure of wolframite-type $\mathrm{FeWO}_{4}$ (cations color: (grey) tungsten, (light-brown) iron, and (red) oxygen). c. Phase diagram of mixed Fe/W oxide (1:1) thin film sputtered at $1.2 \mathrm{~W} . \mathrm{cm}^{-}$ ${ }^{2}$, room temperature and, for different oxygen content and pressure. Films were annealed post-deposition at $600^{\circ} \mathrm{C}$ during $2 \mathrm{~h}$ under vacuum (Dash lines are a guide to the eye). d. XRD patterns of the $\mathrm{FeWO}_{4}\left(+\mathrm{WO}_{3}\right.$ ) region (zone III and IV). 

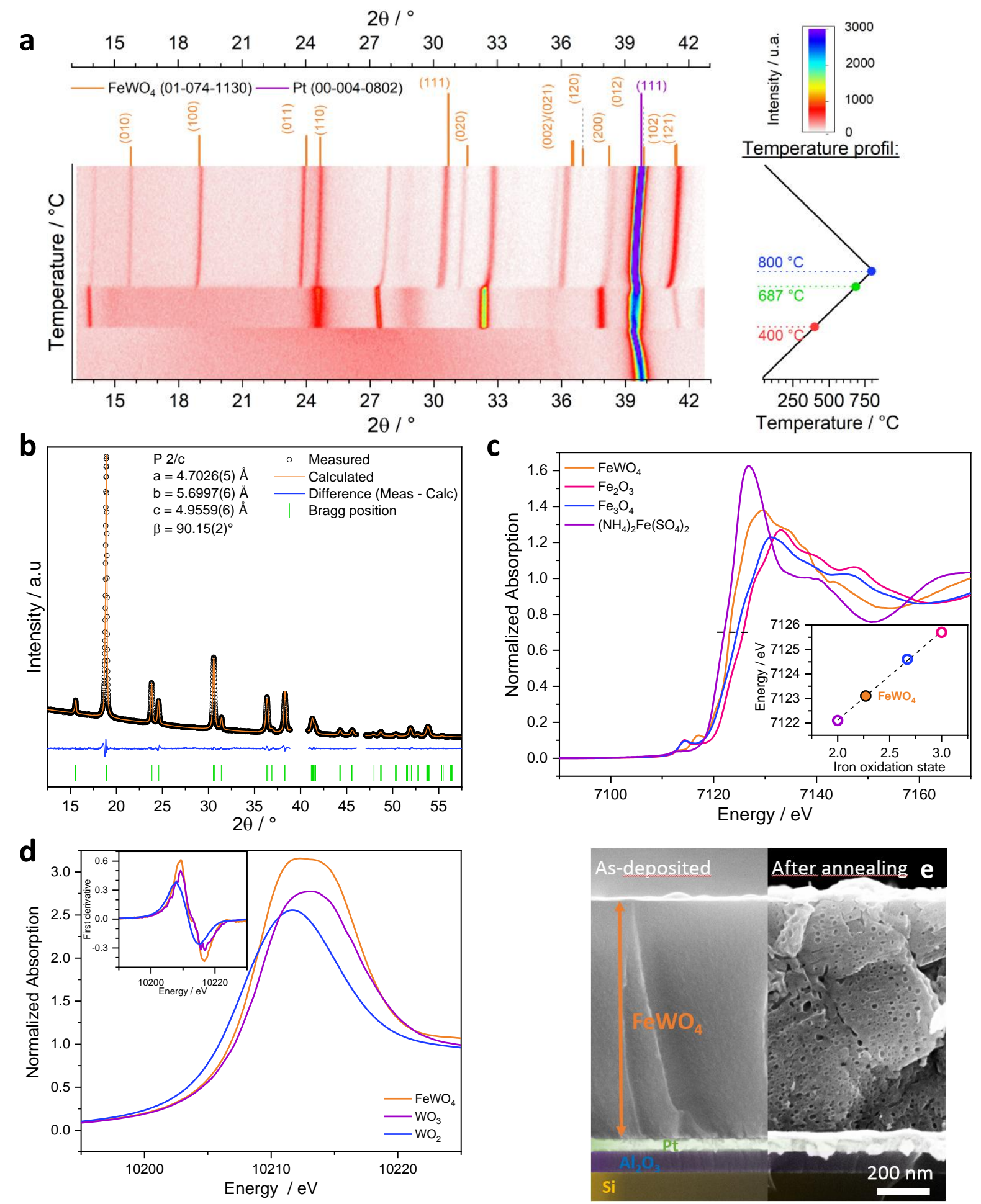

Fig. 2 | a. High temperature in situ $x$-ray thermodiffraction from room temperature to $800^{\circ} \mathrm{C}$ under vaccum, for the as-deposited Fe/W film sputterered at $1.2 \mathrm{~W} . \mathrm{cm}^{-2}$, room temperature, time deposition of 15 minutes, $10 \%$ of oxygen diluted in argon and a pressure of 0.006 mbar. Structural and micro-structural characterization of the said- 
film annealed in tubular furnace at $600^{\circ} \mathrm{C}$ during $2 \mathrm{~h}$ under inert vacuum atmosphere:

b. Le bail refinement, c-d. X-ray Absorption Near Edge Spectroscopy at Fe K-edge

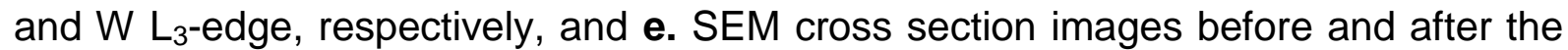
annealing process. 

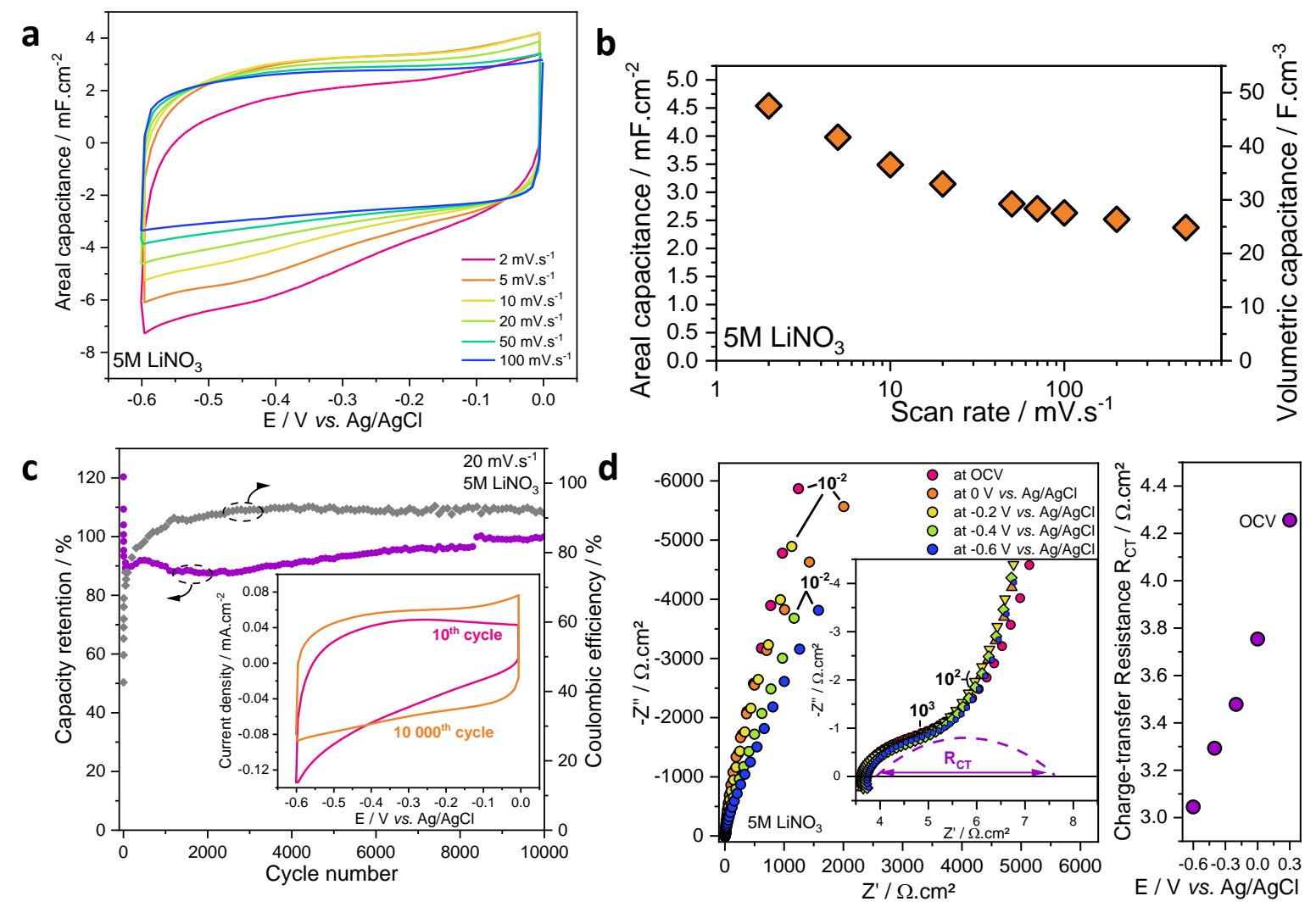

Fig. 3 | Electrochemical characterization of $\mathrm{FeWO}_{4}$ films in neutral aqueous electrolyte (5M $\left.\mathrm{LiNO}_{3}\right)$. a-b. $\mathrm{CV}$ plots at different sweep rates and, the corresponding areal and volumetric capacitance. c. Capacity retention and coulombic efficiency as a function of the cycle number (inset, CVs of the $10^{\text {th }}$ and $10000^{\text {th }}$ cycles). d. Electrochemical Impedance Spectroscopy (inset, a zoom in the high frenquencies zone) at different potential, and the charge transfer resistance values. 

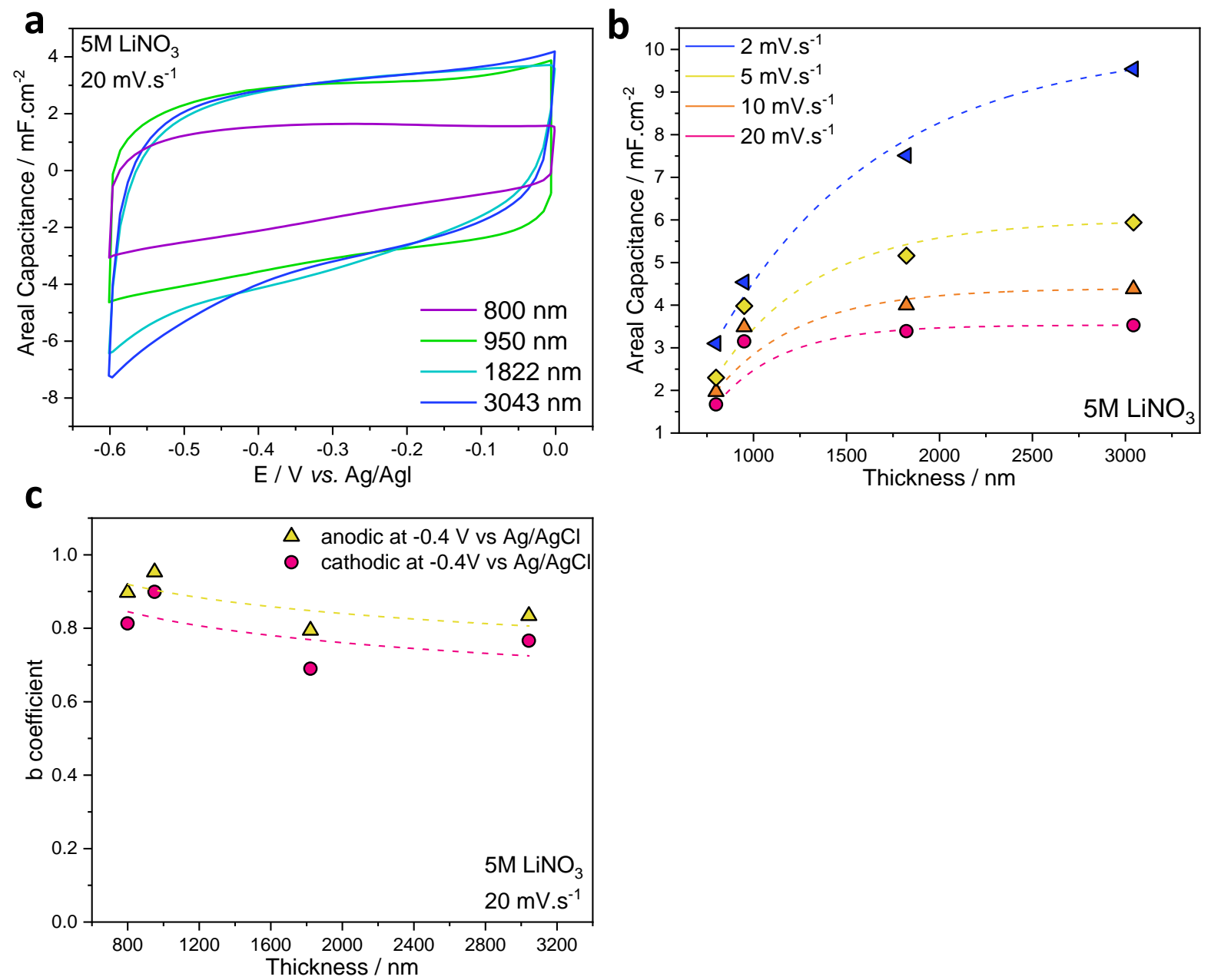

Fig. 4 | Electrochemical characterization of $\mathrm{FeWO}_{4}$ films for different thicknesses ranging from ca. 800 to $3000 \mathrm{~nm}$. a. Cyclic voltammetry at $20 \mathrm{mV} . \mathrm{s}^{-1}$ in $5 \mathrm{M} \mathrm{LiNO}_{3}$. b. Evolution the areal capacitance as a function of the thickness and the sweep rate. c. Determination of the power law b-coefficient as a function of the thickness. 


\section{Supporting Information}
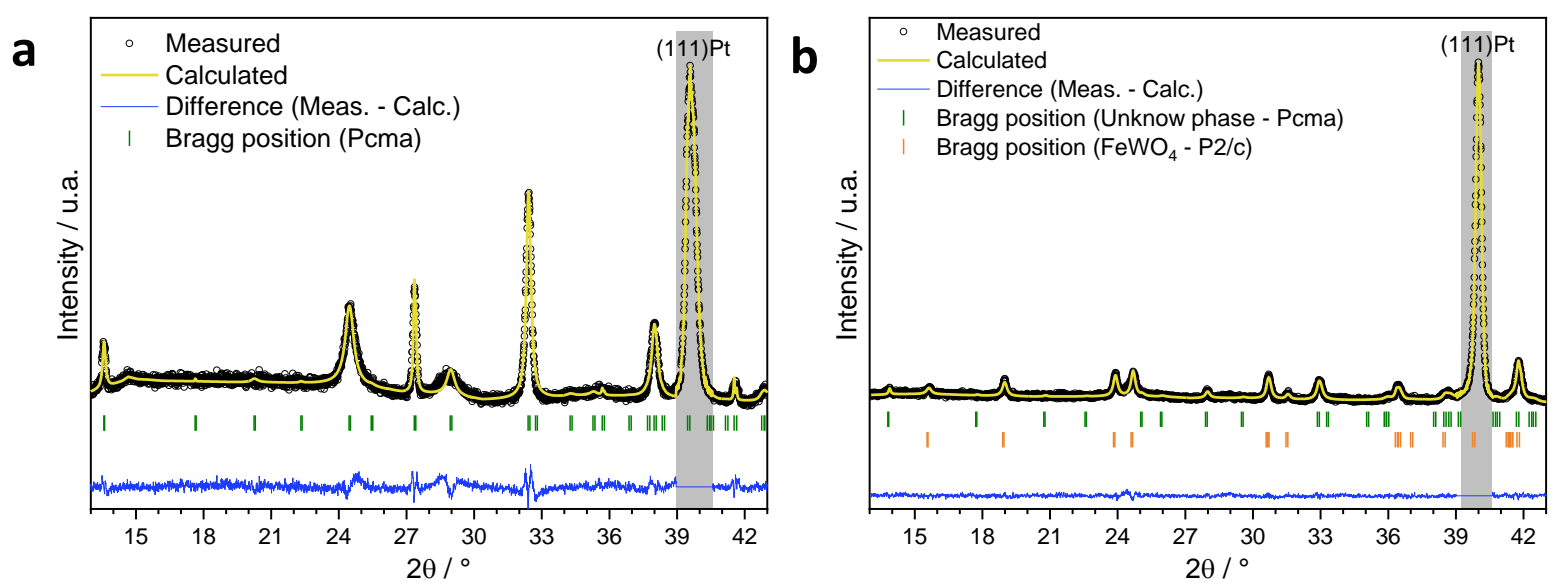

Fig. S1 | Indexation of the intermediate reaction phase during $\mathrm{FeWO}_{4}$ crystallization. Indexation with an orthorhombic structure (space group Pcma) of the intermediate phase observed during thermodiffraction of the mixed Fe/W film, a. at $550^{\circ} \mathrm{C}$ (cell parameters $\mathrm{a}=10.058 \AA, b=6.519 \AA$ and, $\mathrm{c}=4.872 \AA$ ), and $\mathbf{b}$. back to room temperature (cell parameters $a=9.977 \AA, b=6.336 \AA$ and, $c=4.723 \AA$ ). 

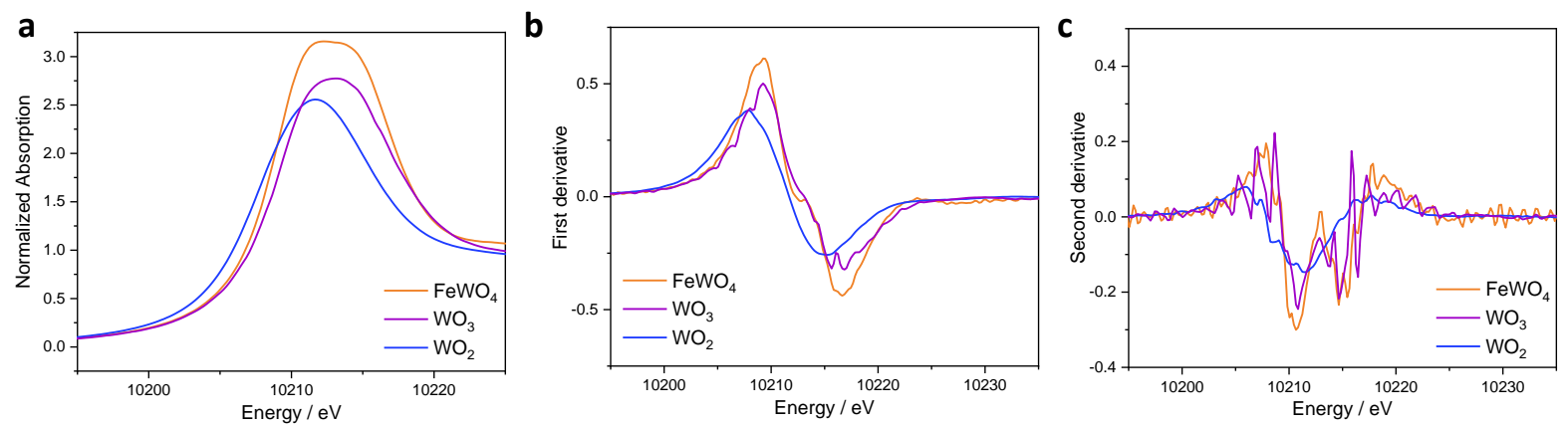

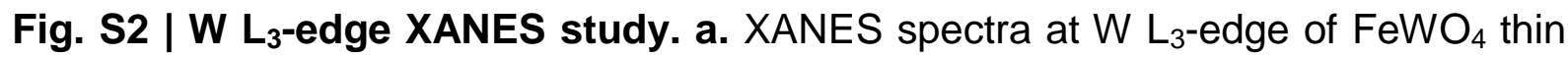
film, $\mathrm{WO}_{3}$ and $\mathrm{WO}_{2}$. b-c. are its first and second derivative, respectively. The splitting of $5 d$ levels into $t_{2 g}$ and $e_{g}$ states is seen by the double peak structure of the second derivate for both $\mathrm{FeWO}_{4}$ and $\mathrm{WO}_{3}$. 

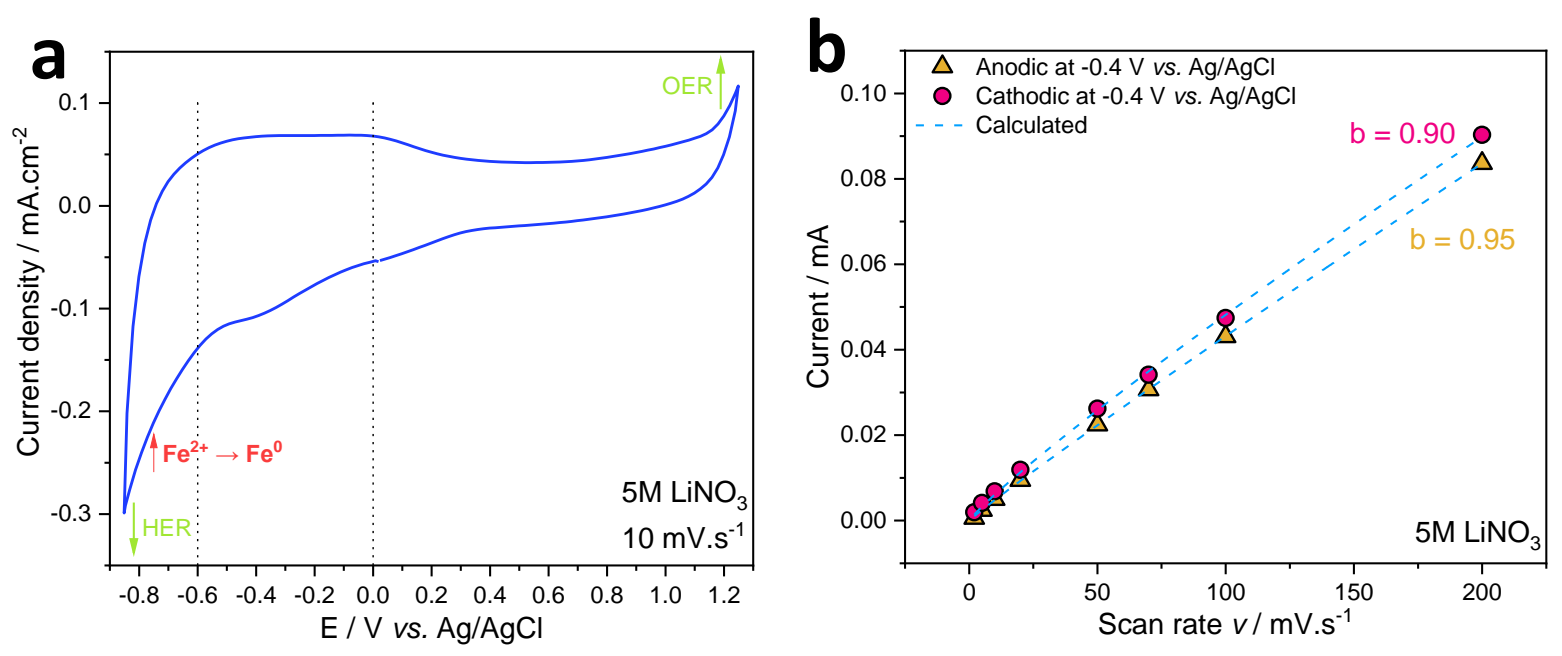

Fig. S3 | a. Electrochemical window stability of sputtered $\mathrm{FeWO}_{4}$ film in $5 \mathrm{M}$ $\mathrm{LiNO}_{3}$. Its stability is limited at the negative and positive potential by Hydrogen Evolution Reaction (HER) and Oxygen Evolution Reaction (OER) of water, respectively. At $0.75 \mathrm{~V}(\mathrm{vs}$. $\mathrm{Ag} / \mathrm{AgCl})$ occurs the irreversible reduction of iron $2+$ into metallic according to the Pourbaix diagram ${ }^{1}$. b. Calculation of the kinetics of the electrolyte ions within the sputtered $\mathrm{FeWO}_{4}$ film from the power law relationship with the sweep rate: $I_{\text {peak }}=a \cdot v^{b}$ where $v$ is the potential sweep rate $\left(\mathrm{mV} \cdot \mathrm{s}^{-1}\right), \mathrm{I}$ the current $(\mathrm{A})$, and $\mathrm{a}, \mathrm{b}$ parameters related to the electrode), the $\mathrm{b}$ coefficient was extracted at the potential $-0.4 \mathrm{~V} v s$. $\mathrm{Ag} / \mathrm{AgCl}$. The b-values close to one indicate a fast charge storage process not limited by the diffusion.

\footnotetext{
${ }^{1}$ Barnum, D.W., Potential-pH diagrams, J. Chem. Educ., 1982, 59(10), 809
} 

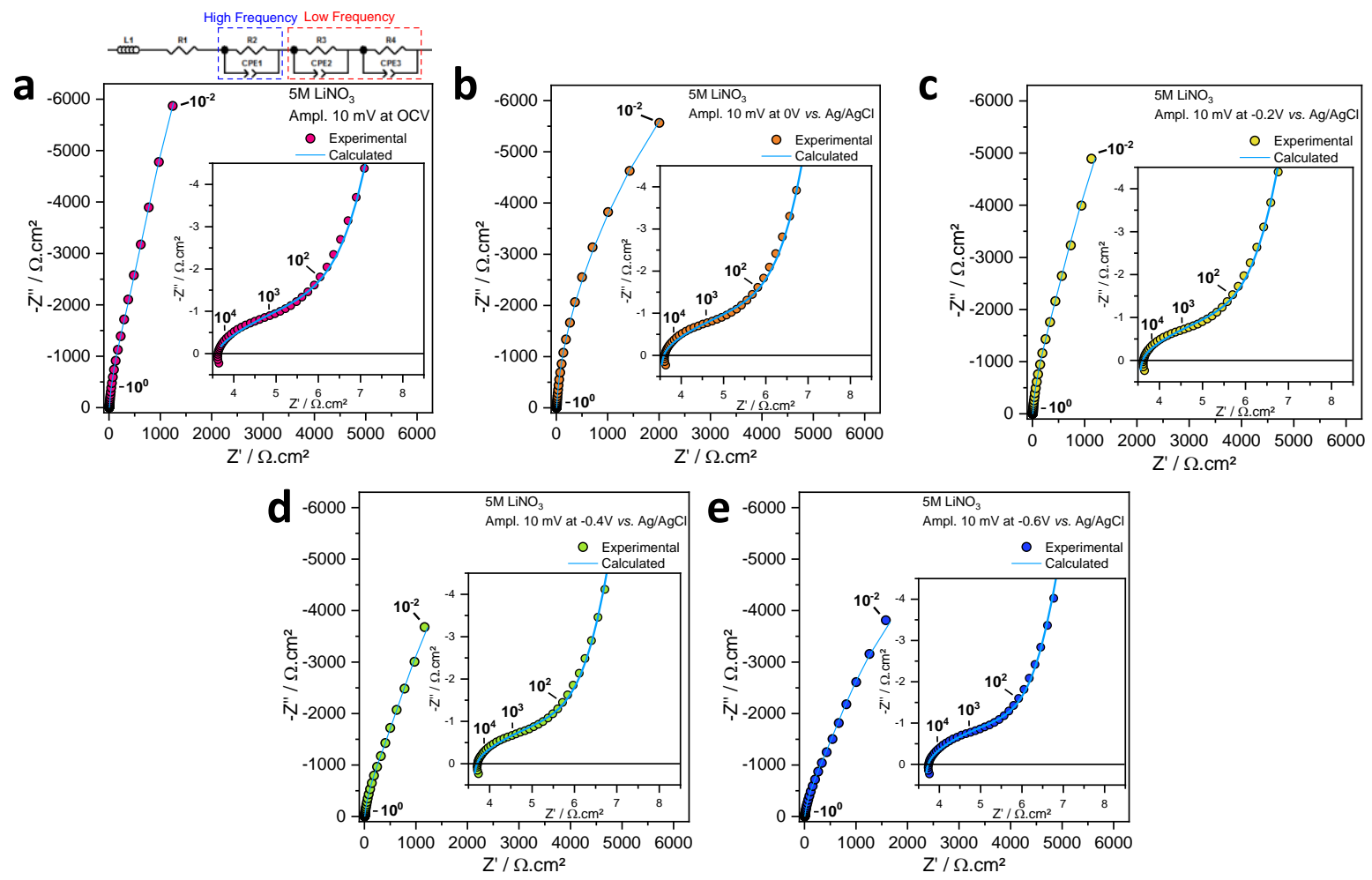

Fig. S4 | Fitting of the Electrochemical Impedance Spectroscopy. a. is the Electrochemical Impedance Spectroscopy measured at OCV. The high frequencies region was fitted with one $\mathrm{R} / / \mathrm{CPE}$ equivalent circuit (where CPE is Constant Phase Element), and the low frequency zone by a simple model associating two R//CPE equivalent circuits. Inductance from the wires/device and the ohmic resistance were fitted with the inductor L1 and the resistance R1, respectively. The following spectra (b. at $0 \mathrm{~V}$, c. at $-0.2 \mathrm{~V}$, d. at $-0.4 \mathrm{~V}$ and, e. at $-0.6 \mathrm{~V} v$ s. $\mathrm{Ag} / \mathrm{AgCl}$, respectively) were fitted according to this model. 

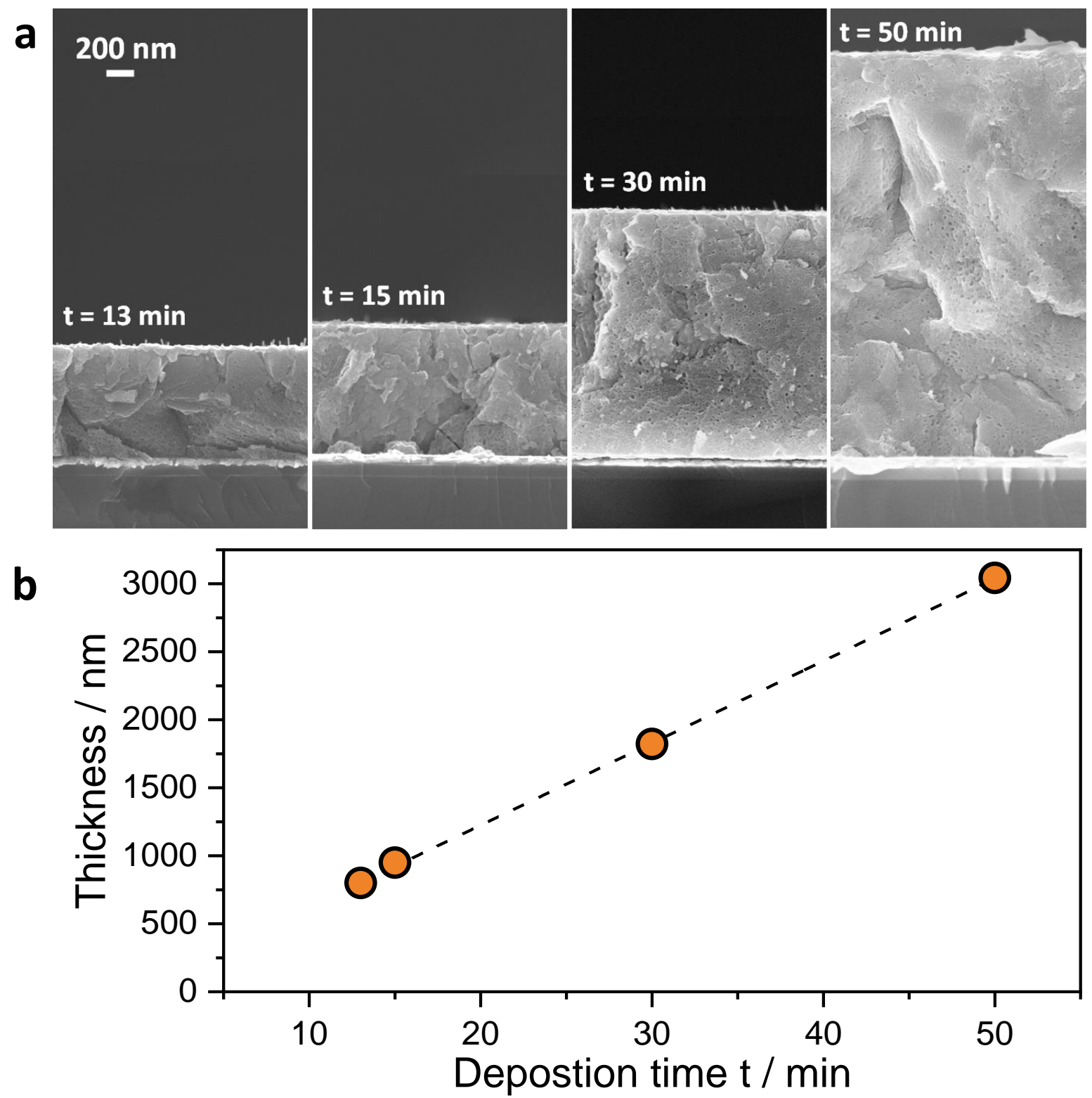

Fig. S5 | Films thicknesses and microstructures. a. SEM cross section images of $\mathrm{FeWO}_{4}$ films with different thicknesses (time deposition). b. Evolution of the film thickness as a function of the deposition time used to evaluate the equivalent growth rate. 